\title{
GÊNERO Cryptostegia: FITOQUÍMICA, ATIVIDADES BIOLÓGICAS E APLICAÇÕES INDUSTRIAIS
}

\author{
Selene M. de Morais ${ }^{\mathrm{a}, *}, \odot$, Hamanda B. Pinheiro ${ }^{\mathrm{a}}$, José V. Rebouças-Filho ${ }^{\mathrm{a}}$, Gessica S. Cavalcante ${ }^{\mathrm{a}}$ e Oriel H. Bonilla ${ }^{\mathrm{a}}$ \\ ${ }^{a}$ Universidade Estadual do Ceará, 60714-903 Fortaleza - CE, Brasil
}

Recebido em 18/09/2020; aceito em 19/01/2021; publicado na web em 18/02/2021

\begin{abstract}
CRYPTOSTEGIA GENUS: PHYTOCHEMISTRY, BIOLOGIAL ACTIVITIES AND INDUSTRIAL APPLICATIONS. The genus Cryptostegia comprises two species, C. madagascariensis (Bojer) and C. grandiflora (Roxb. Ex R. Br) that belong to the Apocynaceae family and are widely distributed in the tropics, as in Australia, New Zealand, India and Brazil, where they cause great socioeconomic and environmental damage, as they are invaders causing damage, mainly in the cultivation of carnaúba, a native plant of great importance in the wax and derivatives industry in Northeast Brazil. Both are perennial shrubs, native to the island of Madagascar, have abundant latex and are known as rubber vine. The plants have the potential for pharmacological, biological and industrial applications. This is due to a rich source of chemical compounds (proteins, phenols, flavonoids, steroids, triterpenoids, cardiac glycosides, etc.) resulting from primary and secondary metabolism. The plants of the Cryptostegia genus showed many activities against bacteria, fungi, insects, Ae. aegypti larvae, Shistosoma sp., as well as for human health as analgesic, anti-inflammatory, antioxidant and antitumoral, and for industrial purposes acting as fibrinogenolytic, hydrolytic, anticorrosive, coagulant and depilatory for leather. Nevertheless, the toxicity is a limitation for the plant use then in order to stand out the economic potential a detailed research on toxicity and management of growing conditions is necessary.
\end{abstract}

Keywords: Apocynaceae; Cardiac glycosides; Medicinal plant.

\section{INTRODUÇÃ̃o}

O gênero Cryptostegia apresenta duas espécies, Cryptostegia madagascariensis (Bojer) e Cryptostegia grandiflora (Roxb. Ex R. Br), da família Apocynaceae. Essas espécies são escandentes perenes, nativas da ilha de Madagascar e possuem látex de forma abundante. ${ }^{1}$ Ambas são popularmente conhecidas como boca-deleão, viuvinha, viúva-alegre, cálice-de-cristo, unha-do-cão, unhado-diabo, unha-do-cão, leiteira, trepadeira, alamanda-roxa entre outros e em idioma inglês como rubber vine. ${ }^{2}$ No Brasil, as duas espécies estão em situação de invasão, afetando os ecossistemas nordestinos, principalmente no ambiente onde ocorre a palmeira endêmica, Copernicia prunifera (Mill.) H. E. Moore, conhecida como "Carnaúba", altamente produtora de cera natural usada na indústria mundial e é uma forte fonte de divisas para o país. ${ }^{3}$

A bioinvasão é uma problemática que vem se agravando no nordeste brasileiro. No estado do Ceará, a espécie $C$. madagascariensis é uma planta muito agressiva que mata a carnaúba por sombreamento e inibição da fotossíntese, causando prejuízo econômico a cadeia produtiva. $^{4}$

As espécies vegetais $C$. madagascariensis e $C$. grandiflora estão distribuídas amplamente nos trópicos, como na Austrália, África, Egito, Marrocos, Ilhas Havaianas, Índia, Ásia, México, Palau, Estados Unidos, França, ilha de Moloka'i, ilha caribenha (Monserrate), Ilhas Fiji e Nordeste do Brasil. Na maioria desses lugares, as espécies ocorrem como invasoras, sendo a causa de tamanha distribuição atribuída ao seu valor ornamental.,

Em contrapartida $C$. grandiflora possui atividades biológicas como antioxidante, anticancerígena e atividades analgésicas. ${ }^{6} \mathrm{O}$ látex de $C$. grandiflora demonstra potencial atividade antifúngica, larvicida, inseticida; fribrogenolítica, hidrolítica, coagulante, dentre outras..$^{7-12}$

Tais atividades são devidas aos diversos compostos químicos que têm potencial medicinal e/ou para aproveitamento industrial, podendo caracterizá-la como de maior valor comercial. ${ }^{13}$ Diante disso,

*e-mail: selenemaiademorais@gmail.com; hamandapinheiro2@hotmail.com é importante reunir e agrupar os estudos referentes aos compostos químicos presentes nas espécies $C$. grandiflora e C. madagascariensis e seus potenciais usos (farmacológicos, biológicos e industriais) para assim embasar futuras pesquisas, a fim de se obter uma visão ampla e esclarecedora sobre as espécies que são consideradas invasoras para poder torná-las, através de um manejo adequado, plantas também úteis.

\section{FONTE DE DADOS}

Para a realização desse trabalho foram consultadas as bases Scinapse, Periódicos Capes, Science Direct e Web of Science. Levou-se em consideração os diferentes estudos, envolvendo caracterização química, atividades biológicas, potenciais utilidades, toxicidade dentre outros usos. Para a busca foram usadas as palavras-chave: Cryptostegia, Cryptostegia grandiflora, Cryptostegia madagascariensis, rubber vine, madagascar rubbervine, woody vine, boca-de-leão, viuvinha, viúva-alegre, unha-do-cão ou unha-do-diabo, alamanda roxa. As pesquisas foram restritas ao intervalo dos anos 1984-2019.

\section{FITOQUÍMICA}

As plantas produzem no seu metabolismo dois tipos de metabólitos denominados primários e secundários. Os primeiros são formados principalmente pelas proteínas, carboidratos e lipídeos que são responsáveis pelo crescimento, reprodução e formação das estruturas de sustentação das plantas. Já os metabólitos secundários constituem as formas de comunicação das plantas com o meio ambiente, no processo de proteção contra a radiação do sol (antioxidantes), contra organismos predadores, como fungos, bactérias e insetos, e na produção de feromônios para polinização e garantir a sobrevivência das espécies. ${ }^{14}$ Estudos realizados com diferentes partes e extratos das duas espécies do gênero Cryptostegia constataram a presença de vários tipos de compostos do metabolismo secundário como fenóis, incluindo flavonoides, taninos e ácidos fenólicos, terpenos, saponinas, 
esteroides, triterpenoides, glicosídeos cardíacos entre outros, que tem potencial para a utilização em processos anti-inflamatórios, como antidiabéticos e analgésicos. ${ }^{15-17}$ Proteínas também foram caracterizadas no látex de $C$. grandiflora e as principais proteinases pertencem ao grupo cisteína. De acordo com Augustus et al. ${ }^{18} C$. grandiflora, além de possuir polifenóis $(6,9 \%)$, possui também 14,0\% de proteína, $6,5 \%$ de triglicerídeos e $2,13 \%$ de hidrocarbonetos. A fração de hidrocarboneto é representada pelo cis-1,4-poliisopreno (borracha natural) e a fração oleosa contém ácidos graxos saturados e insaturados. Os compostos fenólicos são os representantes com maior número de estruturas caracterizadas.

\section{Compostos fenólicos}

Os compostos fenólicos estão cada vez mais despertando interesse por parte da comunidade científica, indústria alimentar e farmacêutica. Já é comprovado que auxiliam processos metabólicos com efeitos benéficos para a saúde e prevenção de doenças como atividades antioxidantes, anticarcinogénicas, antienvelhecimento, antimicrobiana, efeito cardioprotetor e propriedades antiinflamatórias. ${ }^{19-22}$ Dentre os compostos que exercem ação antioxidante e estão presentes em $C$. grandiflora pode-se citar os flavonoides delfinidina (1) e malvidina (2) (Figura 1). ${ }^{23}$
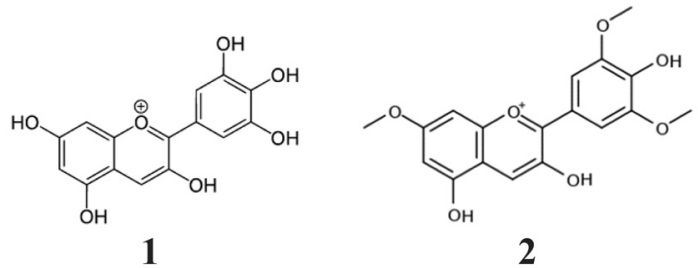

Figura 1. Antocianinas de C. grandiflora

A composição percentual de compostos fenólicos mostrou ser alta no extrato metanólico de $C$. grandiflora que também revelou ser bastante ativo como um anticorrosivo para o aço em meio de $\mathrm{H}_{2} \mathrm{SO}_{4}$ $1 \mathrm{~mol} \mathrm{~L}^{-1}$. A inibição de corrosão do extrato de $C$. grandiflora foi caracterizada por estudos de FT-IR, espectros UV/VIS e DRX; esses mostram a forte interação entre a superfície do metal e o inibidor. ${ }^{15}$

A análise por UHPLC (ultra-high perfromance liquid cromatography) revelou a presença para o extrato metanólico de $C$. grandiflora de vários tipos de compostos fenólicos como citados abaixo cujas estruturas estão mostradas na Figura 2.

i) flavonoides: miricetina (3) rutina (4), quercetina (5) e canferol (6), naringenina (7), formononetina $(\mathbf{8})$, biochanina $\mathrm{A}(\mathbf{9})$, naringina (10), catequina (11) e hesperetina (12),

ii) ácidos hidroxilcinâmicos: ácido ferúlico (13), ácido $o$-cumárico (14), ácido $p$-cumárico (15), ácido $m$-cumárico (16) e ácido clorogênico (17),

iii) ácidos hidroxibenzóicos: ácido gálico (18), ácido protocatecuico (19), ácido siríngico (20) e ácido gentísico (21).

iv) compostos fenólicos em geral: vanilina (22), resveratrol (23), ácido hidroxibenzóico (24).

\section{Esteroides e triterpenos}

Esteróides e triterpenos são compostos frequentes nas plantas e em algumas espécies ambos são sintetizados. Eles também têm uma ampla gama de aplicações comerciais nos setores de alimentos, cosméticos, farmacêutico e biotecnologia industrial. ${ }^{24}$

A partir dos extratos hexânicos e de acetato de etila de $C$. grandiflora foi encontrada uma mistura (Figura 3) dos fitoesteróis $\beta$-sitosterol (25), estigmasterol (26) e campesterol (27), e dos triterpenos lanosterol (28), friedelina (29), lupeol (30), ácido ursólico (31) e $\beta$-amirina (32). ${ }^{25}$

\section{Glicosídeos cardíacos e agliconas (Cardenolideos)}

Glicosídeos cardíacos são compostos contendo um núcleo esteroidal, apresentando neste núcleo duas hidroxilas, uma secundária em C-3 onde normalmente se liga o açúcar e outra terciária em C-14; um hidrogênio ou uma hidroxila em C-5, uma metila em C-13 e um ciclo lactônico $\alpha, \beta$-insaturado na posição C-17. Os glicosídeos cardíacos são uma classe de compostos orgânicos que aumentam a força do coração e sua taxa de contrações, atuando na bomba ATPase de sódio-potássio celular. ${ }^{26}$ Certos glicosídeos cardíacos são usados clinicamente como medicamentos no tratamento de doenças cardíacas e possuem potentes atividades anticâncer mostradas nos ensaios baseados em células e in vivo. ${ }^{27-29}$

Foram isolados das folhas de $C$. grandiflora os seguintes glicosídeos cardíacos, (Figura 4): oleandrigenina 3-O- $\beta$-glicopiranosil- $(1,4)-\beta$ cimaropyranosil- $(1,4)-\beta$-digitoxopiranoside $(33)$, oleandrigenina 3-O- $\beta$-glicopiranosil-( 1,4$)$ - $\alpha$-rhamnopiranosídeo (34), 3-O- $\beta$ glicopiranosil- $(1,4)-\alpha$-rhamnopiranosideo (35) oleandrigenina 3-O- $\beta$-glicopiranosil-(1,6)- $\beta$-glicopiranosil- $(1,4)-\beta$-cimaropiranosil$(1,4)$ - $\beta$-digitoxopiranosideo (36), 16-O-acetil-digitalinum verum (37), subalpinosídeo ou oleandrigenina 3-O- $\beta$-D-glicopiranosil- $(1,4)$ $\beta$-D-digitoxopiranosídeo (38), ${ }^{28}$ criptogandsido A (39) e B $(\mathbf{4 0})^{30}$ e 16-propionilgitoxigenina (41). ${ }^{31}$

Cardenolideos foram isolados e identificados em $C$. grandiflora (Figura 5) como oleandrigenina (42), gitoxigenina (43) e 16-anidrogitoxigenina (44), ${ }^{31}$ enquanto para C. madagascariensis é possível encontrar oleandrigenina (42), 16-anidrogitoxigenina (44) e digitoxigenina (45). ${ }^{29}$

\section{Ácidos graxos}

De acordo com Augustus et al.,${ }^{18}$ C. grandiflora apresenta uma fração oleosa que contém ácidos graxos saturados e insaturados, incluindo: ácido láurico (traços), ácido mirístico (15,24\%), ácido palmítico $(25,90 \%)$, ácido esteárico $(3,8 \%)$, ácido oleico $(8,0 \%)$, ácido linoléico $(24,76 \%)$ e ácido araquídico $(22,28 \%)$. A alta proporção de ácidos graxos saturados e o alto teor de óleo tornam C. grandiflora uma fonte potencial de matéria-prima industrial e alternativa ao óleo convencional.

Os ácidos graxos possuem importante função no setor industrial de alimentos, cosméticos, farmacêutica e na medicina, como é o caso do ácido láurico, que possui atividade antimicrobiana e o ácido palmítico, que possui atividade contra a infecção pelo HIV-1. ${ }^{32}$

\section{ATIVIDADES BIOLÓGICAS E UTILIDADES}

Várias espécies da família Apocynaceae vêm sendo estudadas para melhor compreender suas propriedades, já que muitas são utilizadas como remédio para diferentes sintomas patogênicos, podendo ser, portanto, um objeto de estudo com potencial fonte de novas drogas. ${ }^{33-36}$ Dentro da família Apocynaceae, as espécies C. grandiflora e C. madagascariensis ${ }^{1}$ têm revelado propriedades biológicas e farmacológicas, que incluem atividades antimicrobiana, anti-inflamatória, analgésica, antitumoral, entre outras. ${ }^{6,16,37}$

\section{Atividade antimicrobiana}

Na busca por substâncias potencialmente ativas para medicamentos utilizados no tratamento de doenças infecciosas, testes de sensibilidade bacteriana foram realizados pelo método de microdiluição em 
<smiles>O=c1c(O)c(-c2cc(O)c(O)c(O)c2)oc2cc(O)cc(O)c12</smiles>

3<smiles>O=c1c(O)c(-c2ccc(O)cc2)oc2cc(O)cc(O)c12</smiles>

6<smiles>COc1ccc(-c2coc3cc(O)cc(O)c3c2=O)cc1</smiles><smiles>COc1ccc(C2CC(=O)c3c(O)cc(O)cc3O2)cc1O</smiles>

12<smiles>O=C(O)/C=C/c1ccc(O)cc1</smiles>

15<smiles>O=C(O)c1cc(O)c(O)c(O)c1</smiles>

18

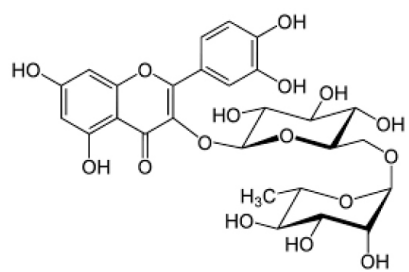

4<smiles>O=C1CC(c2ccc(O)cc2)Oc2cc(O)cc(O)c21</smiles>

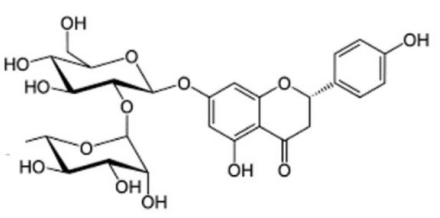

10<smiles>COc1cc(/C=C/C(=O)O)ccc1O</smiles>

13<smiles>O=C(O)C=Cc1cccc(O)c1</smiles>

16<smiles>O=C(O)c1ccc(O)c(O)c1</smiles>

19<smiles>O=c1c(O)c(-c2ccc(O)c(O)c2)oc2cc(O)cc(O)c12</smiles>

5<smiles>COc1ccc(-c2coc3cc(O)ccc3c2=O)cc1</smiles>

8<smiles>Oc1cc(O)c2c(c1)O[C@H](c1ccc(O)c(O)c1)[C@H](O)C2</smiles>

11<smiles>O=C(O)/C=C/c1ccc(O)cc1</smiles>

14<smiles>O=C(/C=C/c1ccc(O)c(O)c1)OC1CC(O)(C(=O)O)CC(O)C1O</smiles>

17<smiles>COc1cc(C(=O)O)cc(OC)c1O</smiles>

20<smiles>O=C(O)c1cc(O)ccc1O</smiles>

21<smiles>COc1cc(C=O)ccc1O</smiles>

22<smiles>Oc1ccc(/C=C/c2cc(O)cc(O)c2)cc1</smiles>

23<smiles>O=C(O)c1ccc(O)cc1</smiles>

24

Figura 2. Representação estrutural dos compostos fenólicos presentes em C. grandiflora

caldo com o extrato etanólico das folhas de $C$. grandiflora, que se mostrou ativo em cepas bacterianas patogênicas de Staphylococcus aureus, Klebsiella pneumoniae e Pseudomonas aeruginosa com porcentagens de inibição superiores a $20 \%$. Tal atividade refere-se à presença de metabolitos secundários apresentados pela planta, como leucoantocianidinas, terpenos, esteroides, taninos e principalmente glicosídeos. ${ }^{16}$

O extrato etanólico de $C$. grandiflora também foi testado atraves do método de difusão em disco nas bactérias: Escherichia coli, Enterobacter cloacae, Klebsiella pneumoniae, Pseudomonas aeruginosa e Proteus vulgaris. Foi testado também em fungos: Aspergillus fumigatus, Penicillium chrysogenum, Rhizoctonia phaseoli, Rhizopus stolonifer e Candida albicans. Dos fitoesteróis (lanosterol, $\beta$-sitosterol, estigmasterol, campesterol) e triterpenoides (friedelina, lupeol, ácido ursólico e $\beta$-amirina) isolados, o lanosterol é o mais ativo (IZ-19.2; AI-1.032) contra Escherichia coli e o campesterol teve maior atividade contra Candida albicans (IZ-15.6; AI-1.006). ${ }^{25}$ 


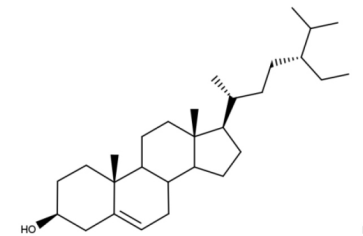

25

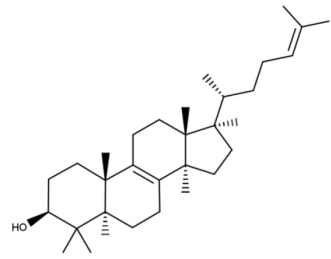

28

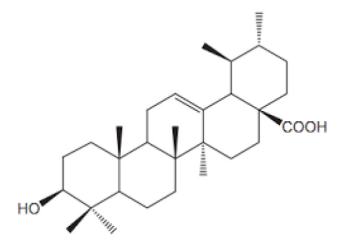

31

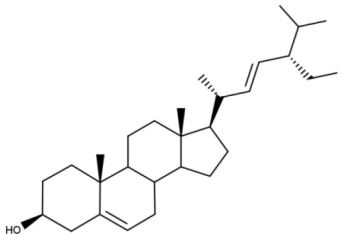

26

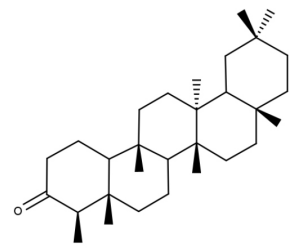

29<smiles>CC(C)CCCC(C)C1CCC2C3CCC4(C)CCC(C)CC4C3(C)CCC12C</smiles>

27<smiles>C=C(C)[C@@H]1CC[C@]2(C)CC[C@]3(C)[C@@]4(C)CCC5C(C)(C)[C@@H](O)CC[C@]5(C)[C@H]4CC[C@]3(C)[C@H]12</smiles>

30

Figura 3. Representação estrutural dos fitoesteroides e triterpenoides isolados de C grandiflora

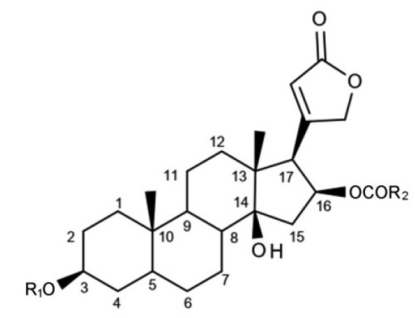<smiles>CC1(C)CC[C@]2(C)CC[C@]3(C)C(=CCC4[C@@]5(C)CC[C@H](O)C(C)(C)C5CC[C@]43C)C2C1</smiles>

32

$$
\begin{array}{cc}
\mathbf{R}_{\mathbf{1}} & \mathbf{R}_{\mathbf{2}} \\
-\mathrm{Dig} \stackrel{4}{\mathrm{Cim}} \stackrel{4}{-\mathrm{Glc}} & -\mathrm{CH}_{3} \\
-\mathrm{Ra} \stackrel{4}{\mathrm{GLc}} & -\mathrm{CH}_{3} \\
-\mathrm{Ra} \stackrel{4}{-\mathrm{Glc}} & -\mathrm{CH}_{2}-\mathrm{CH}_{3} \\
-\mathrm{Dig} \mathrm{C} \stackrel{4}{-\mathrm{Cim}} \stackrel{-}{-\mathrm{Glc}} \stackrel{4}{-\mathrm{Glc}} & -\mathrm{CH}_{3} \\
-\mathrm{Dig} \stackrel{4}{-} \mathrm{Glc} & -\mathrm{CH}_{3} \\
-\mathrm{Glc} \stackrel{4}{-} \mathrm{Dig} & -\mathrm{CH}_{3}
\end{array}
$$

Dig: $\beta$-digitoxipiranose, Cim: $\beta$-cimaropiranose, Ra: $\alpha$-ramnose, Glc: $\beta$-glucopiranose

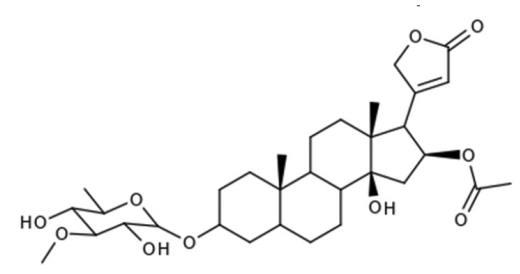

39

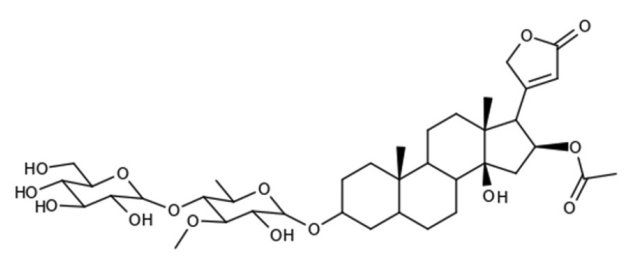

40

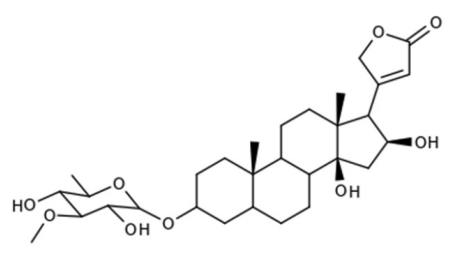

41

Figura 4. Representação estrutural dos glicosídeos cardíacos encontrados em C. grandiflora

Já para um estudo com proteína purificada do látex de $C$. grandiflora (Cg24-I), foi avaliada a atividade antifungica com base na inibição do crescimento de micélios e na germinação de esporos. A Cg24-I inibiu completamente a germinação de esporos de fungos fitopatogênicos Fusarium solani. Esses resultados mostram que as peptidases de látex fazem parte da estratégia defensiva da planta contra fitopatógenos e que elas provavelmente agem sinergicamente envolvendo vários tipos de proteínas que são comumente localizadas em seus latíces. ${ }^{38}$

\section{Atividade inseticida}

Na presença de fitopatógenos como fungos, bactérias e vírus, e também herbívoros como besouros e lagartas, as plantas possuem a necessidade de se defender e fazem isso através de mecanismos defensivos especializados, a presença de látex é um exemplo disso. Tal atividade é apoiada pelo perfil fitoquímico encontrado em diferentes látices, como: terpenóides, cardenolídeos, fenóis, proteases, entre outros. ${ }^{39}$ 


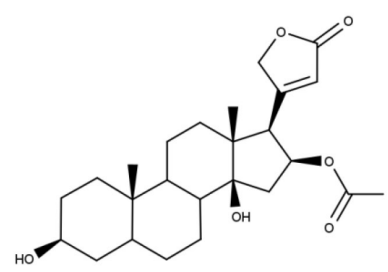

42

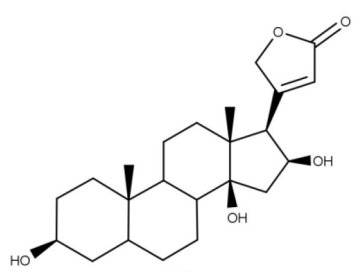

43

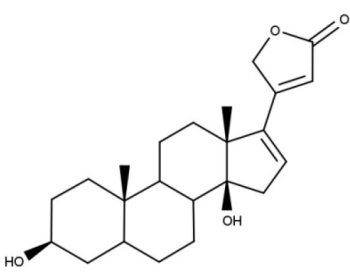

44

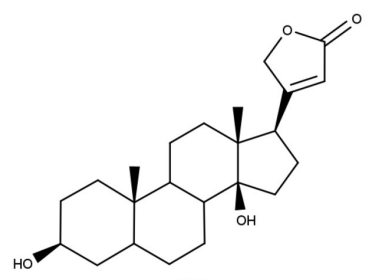

45

Figura 5. Representação estrutural dos cardenolídeos encontrados em C. grandiflora e C. madagascariensis

Em um estudo de avaliação da atividade repelente de diferentes espécies laticíferas em duas espécies de Coleoptera (Bruchidae) que são consideradas pragas (Callosobruchus maculatus e Zabrotis subfasciatus, são exemplos) o látex de C. grandiflora foi um dos menos efetivos, dentre as outras plantas estudadas, mas ainda ativo graças à presença principalmente de alcaloides e glicosídeos fenólicos. ${ }^{8}$

\section{Atividade larvicida}

A dengue é uma doença preocupante e cujas ocorrências vêm se tornando mais críticas a cada ano no Brasil e no mundo tropical, logo a busca por novas fontes naturais de combate a propagação vem crescendo. ${ }^{40}$

O estudo realizado por Ramos et al. mostrou que a fração proteica de $C$. grandiflora possui forte toxicidade larval para Aedes aegypti L. (vetor da doença), isso porque o efeito das proteínas laticíferas na eclosão de ovos apresentou 98,33\% de mortalidade larval após $72 \mathrm{~h}$. Logo a atividade de enzimas proteolíticas de $C$. grandiflora demonstra potencial como agentes químicos para destruir efetivamente larvas de A. aegypti. O estudo sugere que a cisteína-proteinase (EC 3.4.22) possa estar envolvida na ação larvicida contra Aedes aegypti. ${ }^{7}$

\section{Atividade esquistossomicida}

$\mathrm{Na}$ busca para descobrir uma fonte para um medicamento contra esquistossomose que é uma doença causada por vermes trematódeos do gênero Schistosoma, o extrato metanólico dos galhos de $C$. grandiflora foi submetido à triagem de bioensaio em vermes maduros viáveis de Schistosoma mansoni Sambon (Schistosomatidae) e apresentou uma $\mathrm{CL}_{50}=11,4 \mu \mathrm{g} \mathrm{mL}^{-1}$, demonstrando potencial ação que merece uma investigação mais aprofundada para a descoberta de drogas anti-esquistossomose. ${ }^{41}$

C. grandiflora possui o flavonoide hesperitina em sua composição. ${ }^{15} \mathrm{O}$ composto foi investigado e demonstrou atividade esquistossomicida in vitro, contra as formas jovens e vermes adultos de $S$. mansoni nas concentrações de 100, 200 e $600 \mu \mathrm{g} \mathrm{mL} \mathrm{m}^{-1} .^{42} \mathrm{Em}$ outro estudo com a hesperidina obteve-se a redução de vermes e de ovos em tecidos in vivo, principalmente após à infecção por $S$. mansoni, sugerindo que a fase juvenil é mais vulnerável. ${ }^{43}$

Quercetina é outro flavonoide presente em C. grandiflora $^{15}$ que apresentou atividade esquistossomicida in vitro em $S$. mansoni revelando que esse composto foi capaz de promover redução moderada da atividade motora dos vermes em concentrações maiores que $50 \mu \mathrm{g} \mathrm{mL}{ }^{-1}{ }^{44}$

\section{Atividade analgésica}

C. grandiflora faz parte do arsenal de plantas utilizadas para fins analgésicos. Tal atividade foi avaliada em ratos a partir do extrato metanólico das folhas de C. grandiflora dissolvido em DMSO a $1 \%$ na dose de 250,500 e $750 \mathrm{mg} \mathrm{kg}^{-1}$ de peso corporal. ${ }^{6} \mathrm{O}$ extrato não apresentou sinais de toxicidade. Os efeitos analgésicos se mostraram significativos, apoiando a reivindicações medicinais tradicionais sobre $C$. grandiflora, atribuindo-se significativa redução da dor à presença de saponinas, terpenóides, compostos fenólicos, flavonoides e alcaloides. ${ }^{6,45,46}$

\section{Atividade antioxidante}

Vários compostos antioxidantes são obtidos de produtos naturais, particularmente de origem vegetal, devido sua capacidade para a remoção de radicais livres e a inibição da formação de espécies reativas durante o curso normal do metabolismo, que podem prevenir a ocorrência de danos nos lipídeos, proteínas e ácidos nucleicos levando a lesões celulares e morte. ${ }^{47}$ Em extratos metanólicos de $C$. grandiflora, a propriedade antioxidante foi atribuída à presença de compostos fenólicos bem como às enzimas antioxidantes hepáticas, como a catalase $\left(13,09 \pm 0,20 \mu \mathrm{g} \mathrm{mL}^{-1}\right)$, a peroxidase $\left(17,17 \pm 0,07 \mu \mathrm{g} \mathrm{mL}^{-1}\right)$ e a superóxido dismutase $\left(0,17 \pm 0,01 \mu \mathrm{g} \mathrm{mL}^{-1}\right)$ e na proteção contra danos na molécula de DNA causados pelos radicais hidroxila gerados pelo reagente de Fenton (pUC19). ${ }^{23}$ Também foi detectada forte atividade antioxidante das enzimas superóxido dismutase (EC 1.15.1.1), ascorbato peroxidase (EC 1.11.1.1) e, em menor grau, isoformas de peroxidase, no látex de Parte superior do formulário C. grandiflora ${ }^{48}$

Em estudos com outras plantas da família Apocynaceae, os resultados vão de encontro à $C$. grandiflora. Calotropis gigantea (L.) $\mathrm{R}$. Br (Apocynaceae) também apresenta atividade antioxidante em extratos aquosos de várias partes da planta, sendo atribuída à atividade a presença de compostos fenólicos e flavonoides. ${ }^{49}$

\section{Atividade antitumoral}

Um estudo com o extrato alcoólico de ramos finais da copa de C. madagascariensis demonstrou ação inibitória contra a cultura celular $(\mathrm{KB})$ do carcinoma humano da nasofaringe. $\mathrm{O}$ fracionamento sistemático do extrato mostrou que principalmente oleandrigenina, gitoxigenina e rodexina B (glicosídeos cardíacos) eram significativamente ativas, que são em parte responsáveis pela citotoxicidade. $^{31}$

Os glicosídeos cardíacos são compostos naturais amplamente utilizados no tratamento de várias condições cardíacas e, mais recentemente, têm sido reconhecidos como potenciais compostos

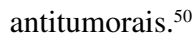

O extrato metanólico da folha de $C$. grandiflora também mostrou atividade antiproliferativa contra a linha celular de adenocarcinoma colorretal (Caco-2), obtendo-se uma atividade moderada. Tal atividade foi atribuída à presença de metabolitos secundários como alcaloides e terpenóides diante do seu efeito sinérgico. ${ }^{23}$

\section{Atividade anti-inflamatória}

C. grandiflora revelou atividade anti-inflamatória em ratos a partir do extrato etanólico das folhas, utilizando modelos in vitro e in vivo de inflamação (com uma solução de acetona contendo o extrato/frações de 
folhas de C. grandiflora ( $1 \mathrm{mg} /$ orelha em $20 \mu \mathrm{L}$ de veículo). A atividade foi relacionada à inibição da atividade da mieloperoxidase (MPO), à produção de prostaglandina E2 (PGE2) e óxido nítrico $(\mathrm{NO} \bullet)$ em macrófagos RAW 264.7. Os autores creditam essa atividade à presença de flavonoides, mas que seriam ainda necessárias mais pesquisas para identificar os compostos anti-inflamatórios específicos. ${ }^{37}$ Outros estudos sugerem que o ácido clorogênico e rutina são responsáveis, pelo menos em parte, por efeitos anti-inflamatórios da espécie Hancornia speciosa que também pertence à família Apocynaceae, ambos os compostos estão presentes em $C$. grandiflora $^{33}$

\section{Aplicações gerais}

\section{Atividade fibrinogenolítica}

Extratos vegetais contendo proteases são utilizados na medicina tradicional para interromper o sangramento e para cicatrização de feridas, possuindo potência homeostática. Logo, as propriedades procoagulantes das proteases constituem um assunto de interesse. Existem algumas proteases de látex e frações de proteínas que diminuem o tempo de coagulação. ${ }^{51}$ Estudos sugerem que as principais proteinases presentes no látex de $C$. grandiflora pertencem ao grupo cisteína. ${ }^{48}$

O látex de Cryptostegia grandiflora (CgLP) juntamente com sua fração de proteínas proteolíticas (CgLP PI) foram capazes de hidrolisar a azocaseína, acelerar a formação do coágulo plasmático e digerir todas as cadeias de fibrinogênio, sugerindo que as atividades fibrinogenolíticas e procoagulantes (realizadas no corpo humano pela plasmina e trombina respectivamente) de $C$. grandiflora foram realizadas por proteases de cisteína e confirmam a atividade como proteínas do tipo trombina e plasmina. Trazendo novas perspectivas sobre o potencial farmacológico de proteases dessa planta na homeostase sanguínea e reforça a atividade fibrinogenolítica associada a proteases de cisteína em látex. ${ }^{9}$

Em estudos anteriores, descobriu-se que outras espécies vegetais da família Apocynaceae possuem proteases que apresentam atividades semelhantes à plasmina e à trombina, além da $C$. grandiflora: Asclepias curassavica L., Cynanchum puciflorum R. Br. e C. gigantea. ${ }^{52}$

\section{Atividade hidrolílica}

A ação hidrolítica das peptidases tem sido aplicada para obter modificações químicas em vários produtos, incluindo alimentos, gerando novos produtos com melhor qualidade sensorial e nutricional. ${ }^{53}$

Na busca por moléculas eficientes para a hidrólise de proteínas no leite de vaca, para a produção de fórmulas hipoalergênicas, avaliou-se o látex $C$. grandiflora como uma nova fonte de peptidases capazes de hidrolizar proteínas no leite de vaca. As peptidases do látex de C. grandiflora (CgLP) foram capazes de realizar a hidrólise total de caseínas. Os ensaios in vivo demonstram que as proteínas do leite de vaca hidrolisadas pela $\mathrm{CgLP}$ não exibem reações imunológicas em camundongos alérgicos ao leite de vaca. ${ }^{10}$

\section{Atividade anticorrosiva}

A corrosão é um dos problemas mais devastadores enfrentados pela maioria das indústrias. Avaliou o extrato de $C$. grandiflora pela sua propriedade anticorrosiva em aço. Ele se mostrou um inibidor ecologicamente correto e anticorrosivo para o aço estudado, pois foi capaz de diminuir a taxa de corrosão, graças à formação de uma película protetora na superfície do metal. ${ }^{15}$

\section{Atividade coagulante}

Em um estudo para verificar o potencial uso de frações de látex em espécies vegetais como coagulantes de leite, peptidases de C. grandiflora mostraram potencial como alternativas para o uso de quimosina comercial de origem animal, diante da semelhança entre elas. Os queijos produzidos com a peptidase de látex de $C$. grandiflora apresentaram rendimentos, massas secas e proteínas solúveis semelhantes aos queijos preparados com quimosina animal. Sendo assim, tais enzimas possuem capacidade de coagular o leite, podendo ser utilizada como alternativas à quimosina comercial de origem animal no processo de fabricação de queijos. ${ }^{11}$

\section{Atividade depilatória de couro cru}

A depilação é a fase inicial do processamento do couro para eliminar os pêlos. O sulfeto de sódio $\left(\mathrm{Na}_{2} \mathrm{~S}\right)$ é universalmente aplicado para esse fim. Esse produto químico não apenas gera consequências desfavoráveis ao meio ambiente, mas também afeta a eficácia das estações de tratamento de efluentes. ${ }^{54}$

Cisteina peptidases de látex de $C$. grandiflora $(\mathrm{CgLP})$ foram testadas com o propósito de produzir protocolos inovadores para reduzir ou eliminar o uso de $\mathrm{Na}_{2} \mathrm{~S}$ na depilação de couro. As CgLP mostraram uma atividade significativa contra a elastina dentre os substratos representativos de pele. Entretanto as CgLP presentes são menos eficientes para serem utilizadas em escala piloto quando comparada com a eficiência das peptidases da planta Calotropis procera Aiton. ${ }^{55}$

\section{Matéria-prima industrial}

Devido à necessidade de avaliar e identificar potenciais espécies de plantas com multiuso, a fim de desenvolver culturas alternativas para atender à alta demanda para combustíveis, produtos químicos e matérias-primas industriais, $C$. grandiflora foi avaliada como uma fonte potencial de matéria-prima industrial e alternativa ao óleo convencional. Isso porque a planta contém uma alta proporção de ácidos graxos saturados e alto teor de óleo. $C$. grandiflora cresce abundantemente sem gestão agronômica, o que a torna capaz de reduzir os custos de produção, além de florescer em solos áridos e semiáridos. ${ }^{18}$

\section{Borracha natural}

Cryptostegia sp é listada como fonte promissora de borracha natural, que pode oferecer uma oportunidade para reduzir os impactos ambientais, ajudar a economia local, reduzir a dependência de fontes de petróleo não renováveis e importações de borracha. ${ }^{56}$ Existem até métodos para a extração de borracha do gênero. ${ }^{57}$ Gêneros como Guayule, Manihot e Funtumia já foram explorados para a produção de borracha, mas ao longo dos anos a espécie que possui maior produtividade pertence ao gênero Hevea ${ }^{58}$

\section{Toxicidade}

Foi registrado um caso de consumo de extrato de folhas da planta C. grandiflora que levou a distúrbios gastrointestinais, cardíacos, eletrolíticos e hematológicos em um ser humano. No exame detalhado das folhas semelhantes às que o paciente consumiu, identificou-se nas folhas de $C$. grandiflora a presença de glicosídeos cardíacos. ${ }^{59}$ Outras plantas da mesma família (Apocynaceae) também possuem glicosídeos cardíacos, cujos gêneros são: Adenium, Acokanthera, Strophanthus, Apocynum, Cerbera, Thevetia, Nerium, Carissa, Urechites Gomphocarpus, Calotropis, Pachycarpus, Asclepias, Xysmalobium, Menabea, Periploca ${ }^{60}$

Muitas plantas contendo glicosídeos cardíacos são historicamente conhecidas por serem tóxicas para animais e humanos. ${ }^{61}$ Em casos acidentais pois constatado que o extrato das folhas de C.grandiflora é capaz de induzir a toxicidade em células humanas caracterizada por alterações gastrointestinais, manifestações neurológicas, eletrolíticas, hematológicas e cardíacas. ${ }^{62,24}$ 
No que se refere a animais ruminantes, $C$. grandiflora foi considerada pelos pecuaristas como umas das mais venenosas para o gado, isso porque a ingestão das folhas pode vir a causar mortalidades. $\mathrm{O}$ ocorrido foi registrado nas regiões de Kereyu-Fantale (Oromo) e Awash-Fantale (Afar), sendo que os animais afetados foram: gado, ovelha, cabra e camelo. ${ }^{63}$

Um estudo foi realizado com cabras e ratos para determinar a toxicidade de Cryptostegia sp. Após o óbito desses animais, amostras de tecido foram coletadas para análises histopatológicas. O resultado mostrou degeneração e necrose multifocal das fibras musculares cardíacas, logo, a planta foi considerada com potencial para promover cardiotoxicidade. ${ }^{64}$

De modo geral, os estudos sugerem fortemente que os glicosídeos cardíacos são potentes agentes quimioterápicos e imunoterapêuticos, como também são seletivos e seguros, o que favorece seu desenvolvimento futuro na produção de medicamentos. ${ }^{50}$

\section{CONCLUSÕES}

A partir dessa revisão bibliográfica é possível concluir que as espécies do gênero Cryptostegia possuem um grande potencial, mostrando-se promissoras para diversos fins, sejam esses farmacêuticos ou industriais. Outros estudos são necessários aprofundando as utilidades aqui abordadas, principalmente no que diz respeito às propriedades medicinais da espécie que incluam estudos de sua toxicidade e segurança, isso porque produtos advindos de recursos naturais florísticos, quando bem aproveitados, podem ser de grande valia no setor da saúde e economia da sociedade. Sugere-se com essa revisão a busca por mais conhecimentos acerca do gênero Cryptostegia, incluindo o manejo no meio ambiente, pois ambas as espécies $C$. grandiflora e a $C$. madagascariensis possuem um grande potencial de aplicação, não devendo ser consideradas somente como invasoras e prejudiciais às culturas de plantas úteis como a carnaúba e o pasto dos animais de criação.

\section{REFERÊNCIAS}

1. Klackenberg, J.; Adansonia 2001, 23, 205; Vieira, M. F.; Leite, M. S. O.; Grossi, J. A. S.; Alvarenga, E. M.; Bragantia 2004, 63, 325.

2. Cavalcante, A.; Major, I.; Ambio 2006, 35, 141.

3. Silva, S. M.; Cavalcante, A. M. B.; Anais do IX Congresso de Ecologia do Brasil, São Lourenço, Brasil, 2009.

4. Sousa, L. A.; Guimarães, L. L.; Reis, A. T.; Costa, I. S. C.; Araújo, J. P.; Dias, F. Y. E. C.; Monteiro, C. C.; Bonilla, O. H. Resumos Expandidos do I CONICBIO / II CONABIO / VI SIMCBIO. Recife, Brasil, 2013.

5. Medeiros, J. dos S. de; Mesquita, F. de O.; de Andrade, L. A.; de Oliveira, C. J.; de Souza, E. M.; de Souza, J. K. C.; Pesquisa e Ensino em Ciências Exatas e da Natureza 2018, 2, 36; Silva, A. L.; Salcedo, S. S.; Ribeiro, N. A. S.; Barreto, R. W.; Plant Dis. 2018, 102, 681.

6. Hanumanthappa, S. K.; Hanumanthappa, M.; Venkatarangaiah, K.; Krishnappa, P.; Gupta, R. K. P.; Asian Pac. J. Trop. Dis. 2012, 2, 494

7. Ramos, M. V.; Pereira, D. A.; Souza, D. P.; Araújo, E. S.; Freitas, C. D. T.; Cavalheiro, M. G.; Matos, M, P. V.; Carvalho, A.F. U.; Mem. Inst. Oswaldo Cruz, 2009, 104, 805.

8. Ramos, M. V.; Araújo, E. S.; Oliveira, R. S. B.; Teixeira, F. M.; Pereira, D. A.; Cavalheiro, M. G.; Souza, D. P.; Oliveira, J. S.; de Freitas, C. D. T.; Braz. J. Plant Physiol. 2011, 23, 57.

9. Viana, C. A., Oliveira, J. S., Freitas, C. D., Alencar, N. M., Carvalho, C. P., Nishi, B. C., Ramos, M. V.; Blood Coagulation Fibrinolysis 2013, $24,386$.

10. Oliveira, J. P. B.; Candreva, A. M.; Rizzo, G.; Ramos, M. V.; Oliveira, J. S.; Oliveira, H. D.; Ary, M. B.; Docena, G.; Freitas, C. D. T.; Food Chem. 2019, 284, 245.
11. Freitas, C. D. T.; Leite, H. B.; Oliveira, J. P. B.; Amaral, J. L.; Egito, A. S.; Vairo-Cavalli, S.; Lobo, M. D. P.; Monteiro-Moreira, A. C. O.; Ramos, M. V.; Food Res. Int. 2016, 87, 50; Freitas, C. D. T.; Ramos, M. V.; Leite, H. B.; BR1020150129963, 2015.

12. Vieira, M. F.; Leite, M. S. O.; Grossi, J. A. S.; Alvarenga, E. M.; Bragantia 2004, 63, 325.

13. Abarca, L. F. S.; Klinkhamer, P. G. L.; Choi, Y. H.; Planta Med. 2019, 85,856 .

14. Morais, S. M.; Braz Filho, R.; Produtos Naturais: Estudos Químicos e Biológicos, $1^{\text {a }}$ ed. EdUECE: Fortaleza, 2007.

15. Prabakaran, M.; Kim, S.; Hemapriya, V.; Chung, I.; J. Ind. Eng. Chem. 2016, 37, 47 .

16. Rivera, D. E.; Ocampo, Y. C.; Castro, J. P.; Caro, D.; Franco, L. A.; Orient. Pharm. Exp. Med. 2015, 15, 95.

17. Mali, N.; Javalgikar, A.; Kale, S.; J. Pharma Res. 2018, 5, 82.

18. Augustus, G. D. P. S; Jayabalan, M.; Seiler, G. J.; Ind. Crops Prod. 2000, 11,59 .

19. Hurtado-Fernández, E.; Gómez-Romero, M.; Carrasco-Pancorbo, A.; Fernández-Gutiérrez, A.; J. Pharm. Biomed. Anal. 2010, 53, 1130.

20. Liu, R. H.; J. Food Sci. 2013, 78, 18.

21. Orak, H. H.; Sci. Hortic. 2007, 111, 235.

22. Wiseman, H. Em Encyclopedia of Human Nutrition; Allen L. H., Prentice A., Caballero B., eds.; Academic Press: London, 2013.

23. Santhosh K. H.; Manjunatha, H.; Krishna V.; Swamy K.; Int. J. Pharm. Pharm. Sci. 2014, 5, 156.

24. Thimmappa, R.; Geisler, K.; Louveau, T.; O’Maille, P.; Osbourn, A. Annu. Rev. Plant Biol. 2014, 65, 225.

25. Singh, B.; Sharma, R. A.; Vyas, G. K.; Sharma, P.; J. Med. Plants Res. 2011, 5, 1598

26. Lev, M. C.; Karlish, S. J. D.; Garty, H. Am. J. Physiol, 2015, 309, 135.

27. Diederich, M.; Muller, F.; Cerella, C.; Biochem. Pharmacol. 2017, 125, 11.

28. Kamel, M. S.; Assaf, M. H.; Abe, Y.; Ohtani, K.; Kasai, R.; Yamasaki, K.; Phytochemistry 2001, 58, 537.

29. Sanduja, R.; Lo, W. Y. R.; Euler, K. L.; Alam, M.; Morton, J. F.; J. Nat. Prod. 1984, 47, 260

30. Aebi, A.; Reichstein, T.; Helv. Chim. Acta 1950, 33, 1013.

31. Doskotch, R. W.; Malik, M. Y.; Hufford, C. D.; Malik, S. N.; Trent, J. E.; Kubelka, W.; J. Pharm. Sci. 1972, 61, 570.

32. Vianni, R.; Braz-Filho, R.; Quim. Nova 1995, 19, 400; Kitahara, T.; Koyama, N.; Matsuda, J.; Aoyama, Y.; Hirakata, Y.; Kamihira, S.; Kohno, S.; Nakashima, M.; Sasaki, H.; Biol. Pharm. Bull. 2004, 27, 1321; Lee, D. Y..; Lin, X.; Paskaleva, E. E.; Liu, Y.; Puttamadappa, S. S.; Thornber, C.; Drake, J.R.; Habulin, M.; Shekhtman, A.; Canki, M.; AIDS Res. Hum. Retroviruses 2009, 25, 1231.

33. Torres-Rêgo, M.; Furtado, A. A.; Bitencourt, M. A. O.; Lima, M. C. J. de S.; Andrade, R. C. L. C. de; Azevedo, E. P. de; Soares, T. da C.; Tomaz, J. C.; Lopes, N. P.; da Silva-Júnior, A. A.; BMC Complementary Altern. Med. 2016, 16, 1.

34. Oliveira, N. T.; de Almeida, S. S. M. da S.; Biota Amazônia 2016, 6, 20.

35. Erharuyi, O.; Falodun, A.; Langer, P.; Asian Pac. J. Trop. Med. 2014, 7, 8.

36. Moraes, T. de M.; Rodrigues, C. M.; Kushima, H.; Bauab, T. M.; Villegas, W.; Pellizzon, C. H.; Brito, A. R. M. S.; Hiruma-Lima, C. A.; J. Ethnopharmacol. 2008, 120, 161 .

37. Castro, J. P; Ocampo, Y. C; Franco, L. A.; Biol. Res. 2014, 47, 32.

38. Ramos, M. V.; Souza, D. P.; Gomes, M. T. R.; Freitas, C. D. T.; Carvalho, C. P. S.; R. Júnior, P. A. V.; Salas, C. E.; Protein J. 2014, 33, 199.

39. Konno, K., Phytochemistry 2011, 72, 1510; Taira, T.; Ohdomari, A.; Nakama, N.; Shimoji, M.; Ishihara, M.; Biosci., Biotechnol., Biochem. 2005, 69, 811; Farias, L. R.; Costa, F. T.; Souza, L. A.; Pelegrini, P. B.; Grossi-De-Sá, M. F.; Neto, S. M.; Bloch, C.; Laumann, R. A.; Noronha, E. F.; Franco, O. L.; Pestic. Biochem. Physiol. 2007, 87, 255. 
40. Barreto, M. L.; Teixeira, M. G.; Estudos Avançados 2008, 22, 53.

41. Yousif, F.; Wassel, G.; Boulos, L.; Labib, T.; Mahmoud, K.; El-Hallouty, S.; Bardicy, S. El; Mahmoud, S.; Ramzy, F.; Gohar, L.; Pharm. Biol. 2011, 50, 732 .

42. Allam, G.; Abuelsaad, A. S. A.; J. Helminthol. 2014, 9, 9.

43. El-Aswad, B. E. D. W.; Sadek, G. S.; Life Sci. J. 2014, 11, 840.

44. Braguine, C. G.; Bertanha, C. S.; Gonçalves, U. O.; Magalhães, L. G.; Rodrigues, V.; Gimenez, V. M. M.; Groppo, M.; Silva, M. L. A.; Cunha, W. R.; Januário, A. H.; Pauletti, P. M.; Pharm. Biol. 2012, 50, 925.

45. Yougbaré-Ziébrou, M. N.; Ouédraogo, N.; Lompo, M.; Bationo, H.; Yaro, B.; Gnoula, C.; Sawadogo, W. R.; Guissou, I. P.; Phytothérapie 2015, 14, 213; Dey, A.; Mukherjee, A.; Chaudhury, M.; Stud. Nat. Prod. Chem. 2017, 52, 373.

46. Ishola, I. O.; Agbaje, E. O.; Adeyemi, O. O.; Shukla, R.; Pharm. Biol. 2014, 52, 1208; Ak, T.; Gülçin, İ.; Chem.-Biol. Interact. 2008, 174, 27.

47. Zhang, Y.; Seeram, N. P.; Lee, R., Feng, L., Heber, D.; J. Agric. Food Chem. 2008, 56, 670

48. Freitas, C. D. T.; Souza, D. P.; Araújo, E. S.; Cavalheiro, M. G.; Oliveira, L. S.; Ramos, M. V.; Braz. J. Plant Physiol. 2010, 22, 22.

49. Kadiyala, M.; Ponnusankar, S.; Elango, K.; J. Ethnopharmacol. 2013, $150,32$.

50. Schneider, N.; Cerella, C.; Simões, C. M. O.; Diederich, M.; Molecules 2017, 22, 1932.

51. Balakireva, A. V.; Kuznetsova, N. V.; Petushkova, A. I.; Savvateeva, L. V.; Zamyatnin J., A. A.; Curr. Med. Chem. 2019, 26, 465.

52. Rajesh, R.; Gowda, C. D. R.; Nataraju, A.; Dhananjaya, B. L.; Kemparaju, K.; Vishwanath, B. S.; Toxicon 2005, 46, 84; Shivaprasad,
H. V.; Riyaz, M.; Kumar, R. V.; Dharmappa, K. K.; Tarannum, S.; Siddesha, J. M.; Rajesh, R.; Vishwanath, B. S.; J. Thromb. Thrombolysis 2008, 28, 304.

53. Giacometti, J.; Buretić-Tomljanović, A.; Food Chem. 2017, 230, 91.

54. Dixit, S.; Yadav, A.; Dwivedi, P. D.; Das, M.; J. Cleaner Prod. 2015, 87, 39.

55. Lopéz, L. M. I.; Viana, C. A.; Errasti, M. E.; Garro, M. L.; Martegani, J. E.; Mazzilli, G. A.; Freitas, C. D. T.; Araújo, Í. M. S.; Silva, R. O.; Ramos, M. V.; Bioprocess Biosyst. Eng. 2017, 40, 1391.

56. Rasutis, D.; Soratana, K.; Mcmahan, C.; Landis, A. E.; Ind. Crops Prod. 2015, 70, 383.

57. Mcgavack J.; US 2353460A, 1944; Reif E. O.; Trafton J. M.; US 2413654A, 1946.

58. Venkatachalam, P.; Geetha, N.; Sangeetha, P.; Thulaseedharan, A.; Afr. J. Biotechnol. 2013, 12, 1297.

59. Sangle, S. A.; Inamdar, S.; Deshmukh, V.; J. Assoc. Physicians India 2015, 63, 79 .

60. Morsy, N. Aromat. Med. Plantas 2017, 45.

61. Akinmoladun, A. C.; Olaleye, M. T.; Farombi, E. O. Em Toxicological Survey of African Medicinal Plants; Kuete V., eds.; Elsevier: Camarões, 2014.

62. Kanji, S.; Maclean, R. D.; Crit. Care Clin. 2012, 28, 527.

63. Abule, E.; Snyman, H. A.; Smit, G. N.; J. Environ. Manage. 2005, 75, 21.

64. Nunes, F. C. R.; Batista, J. S.; Soto-Blanco, B.; Res. Vet. Sci. 2011, 90, 474. 